\title{
Avaliação toxicológica do extrato acetato de etila de Spigelia anthelmia Linn, em ratos e camundongos
}

\section{Toxicological evaluation of an ethyl acetate extract of Spigelia anthelmia Linn in rats and mice}

\author{
A. L. F. Camurça-Vasconcelos; L. M. Melo;* N. R. F. Nascimento;" P. G. M. Teixeira; ${ }^{*}$ D. B. Menezes;** R. A. Silva;** \\ I. P. Souza;*** M. G. R. Queiroz; ${ }^{* \star}$ S. M. Morais; $;^{*}$ C. M. L. Bevilaqua*
}

\begin{abstract}
Resumo
O extrato acetato de etila de Spigelia anthelmia (EASa) mostrou formalmente ser altamente eficaz contra o desenvolvimento larvar e a eclosão de ovos de Haemonchus contortus, um importante parasito de ruminantes, in vitro. $\mathrm{A} \mathrm{DL}_{1}$ e a $\mathrm{DL}_{10}$ de $\mathrm{EASa}$ foram administradas subcrônica e cronicamente pela via oral em ratos wistar e o perfil bioquímico foi comparado antes e após cada tratamento e com veículo. Vários órgãos foram coletados e processados para análise histopatológica. Os parâmetros hematológicos foram avaliados antes e depois da administração de EASa durante 30 dias. E os efeitos do EASa administrado pela via oral durante o período embriogênico ou organogênico a camundongas gestantes foram estudados. Os efeitos diretos de EASa, in vivo, foram calculados na pressão sangüínea arterial média e no eletrocardiograma (ECG), e in vitro no coração isolado e no átrio isolado de ratos. A administração de EASa não afetou qualquer parâmetro bioquímico, hematológico ou reprodutivo estudado. EASa induziu um efeito hipotensivo de curto prazo em ratos normotensivos sem qualquer alteração concomitante nos parâmetros do ECG. As maiores doses de EASa induziram uma significante diminuição da amplitude de contração do coração e átrio direito. EASa é desprovido de toxicidade significante e tem leves efeitos no sistema cardiovascular.
\end{abstract}

Palavras-chave: Spigelia anthelmia, toxicidade sistêmica, ratos e camundongos.

\begin{abstract}
Ethyl acetate of Spigelia anthelmia (EASa) was formely shown to be effective against larval development and egg hatching of Haemonchus contortus, an important ruminant parasite, in vitro. The calculated $\mathrm{LD}_{1}$ and $\mathrm{LD}_{10}$ of EASa were administered subchronically and chronically by oral route to Wystar rats and the serum biochemical profile was compared before and after treatments and with the control. Several organs were collected and processed for histopathological examination. Hematological parameters were evaluated before and after administration of EASa during 30 days. The effects of EASa administered by oral route during the embriogenic or organogenic period to pregnant mice were studied. The direct effects of EASa, in vivo, were evaluated on mean arterial blood pressure (MAP) and electrocardiogram (ECG), and in vitro on the isolated heart and atria of rats. The oral administration of EASa, did not affect any of the biochemical, hematological or reproductive parameters. EASa induced only a short-term hipotensive effect in normotensive rats, without any concomitant alteration in ECG parameters. The higher doses of EASa induced a significant decrease in the contraction amplitude of the isolated heart and in the right atria. The EASa is devoid of systemic toxicity and has slight effects on the cardiovascular system.
\end{abstract}

Keywords: Spigelia anthelmia, systemic toxicity, rats and mice.

\section{Introdução}

Spigelia anthelmia é uma erva da família das loganiáceas conhecida no Brasil como "erva-lombrigueira" e é utilizada no Nordeste do Brasil por suas reputadas propriedades antihelmínticas. Estudos prévios mostram que o extrato aquoso e extratos orgânicos desta planta inibem a eclosão de ovos e o desenvolvimento larvar de Haemonchus contortus, o mais importante parasito gastrintestinal de ruminantes do nordeste do Brasil (Batista et al, 1999; Assis, 2000). Entretanto, so- mente informações escassas com respeito ao seu perfil toxicológico estão disponíveis. Braga (1976) e Basílio et al. (2001) reportam que esta espécie é letal para bovinos e induz êmese e convulsões em animais monogástricos. Alguns autores relatam o isolamento de alcalóides quaternários nesta espécie e caracterizaram suas atividades cardiodepressoras em músculo papilar isolado de porquinhos-da- índia (Wagner et al., 1993; Achenbach et al., 1995; Hübner et al., 2001). Camurça-Vasconcelos (2002) avaliaram os efeitos neuromusculares e a toxicidade aguda de um extrato acetato de etila de

\footnotetext{
* Universidade Estadual do Ceará, Av. Paranjana 1700, CEP 60770-000, Fortaleza, Ceará, Brasil. E-mail: claudiam@fortalnet.com.br

** Departamento de Patologia e Medicina Legal, Faculdade de Medicina - UFC

*** Departamento de Análises Clínicas. Faculdade de Farmácia - UFC.
} 
Spigelia anthelmia (EASa) relatando que esta planta induz paralisia tônica in vivo, diminui a amplitude de contração e aumenta o tônus de músculos esqueléticos in vitro.

O objetivo deste trabalho foi avaliar a toxicidade sistêmica e reprodutiva de extrato acetato de etila de Spigelia anthelmia (EASa) relativa a administração por um longo período pela via oral e depois seus efeitos cardiovasculares agudos gerais. A administração de doses repetidas foi realizada com o objetivo de avaliar os efeitos sistêmicos de EASa tendo sido mensurados pela variação de parâmetros bioquímicos específicos, status hematológico e estudo histopatológico dos órgãos principais. $\mathrm{O}$ estudo reprodutivo foi realizado para determinar a potencial embrioletalidade e os efeitos organogênicos ou teratogênicos deste extrato. Os efeitos cardiovasculares foram investigados in vivo na pressão sangüínea arterial média (PAM) e no eletrocardiograma (ECG), e in vitro em coração e átrio isolados perfundidos.

\section{Material e métodos}

\section{Animais \\ Camundongos Albino Swiss e ratos Wistar, oriundos do Biotério do Instituto de Biomedicina da Universidade Federal do Ceará onde foram alojados, tendo livre acesso à água de bebida e alimentação (Fri-Ribe Laboratory Animals Chow Ò). Os desenhos experimentais descritos aqui foram submeti- dos ao comitê de ética local e seguiu as normas para cuida- do e utilização do Instituto de Saúde Nacional dos Estados Unidos. \\ Preparação do extrato acetato de etila de S. anthelmia (EASa)}

A planta foi coletada no campus da Universidade Federal do Ceará e a exsicata está depositada no Herbário Prisco Bezerra sob o número 24.470. As partes aéreas da planta sofreram extração com etanol e submetidas a cromatografia de coluna a vácuo e eluídas com hexano, clorofórmio, acetato e metanol. Após evaporação, o extrato acetato de etila (EASa) foi suspenso em TWEEN 80 a $3 \%$ em salina com objetivo de preparar soluções estoque para os testes farmacológicos.

\section{Toxicidade sistêmica}

Ratos Wistar de ambos os sexos, foram tratados pela via oral, através de gavagem, durante 30 dias (subcrônica). Os animais foram divididos em três grupos ( $n=10 /$ grupo), dos quais o primeiro e o segundo grupo receberam 73,4 e 147,3 $\mathrm{mg} / \mathrm{kg} / \mathrm{dia}$ de EASa, respectivamente, e o terceiro grupo recebeu $1 \mathrm{~mL} / \mathrm{kg} /$ dia de salina + tween (controle). Estas doses de EASa correspondem a $\mathrm{DL}_{1}$ e $\mathrm{DL}_{10}$ obtidas em estudos prévios em camundongos Camurça-Vasconcelos (2002) e o volume fornecido de veículo corresponde ao maior volume de extrato fornecido nos grupos anteriores, e foram empregados no delineamento dos estudos de toxicidade subcrônica ou crônica no que se refere à escolha de doses (Barros e Davino, 1996). Em outro experimento, os animais foram divididos em dois grupos: o primeiro grupo recebeu a dosagem de 147,3 $\mathrm{mg} / \mathrm{kg} / \mathrm{dia}$ de EASa e o segundo grupo recebeu $1 \mathrm{~mL} / \mathrm{kg}$ de salina + tween (controle), sendo que estes animais foram tratados durante 60 dias (toxicidade crônica) pela via oral, através de gavagem. Amostras de sangue foram coletadas antes e após o tratamento para determinação da concentração sérica de uréia, creatinina, albumina, bilirrubina total, bilirrubina direta e indireta, transaminase glutâmica oxalacética (TGO) e transaminase glutâmica pirúvica (TGP) que foram comparadas entre e dentro dos grupos. As amostras de sangue foram coletadas do plexo infraorbital em tubos com gel separador para soro (Vacuette, São Paulo, Brasil) e centrifugadas a $3.000 \mathrm{~g}$ e as análises bioquímicas foram realizadas com o uso de kits disponíveis comercialmente (Labtest, Lagoa Santa, Minas Gerais, Brasil). No final do período experimental, dos animais de todos os grupos foram coletados coração, pulmão, fígado, rins e baço, que foram fixados em formol, processados e corados com HematoxilinaEosina para análise histopatológica.

\section{Toxicidade hematológica}

Ratos Wistar do sexo feminino $(n=6)$ foram tratados durante 30 dias pela via oral, através de gavagem, com 147,3 mg/kg/ dia de EASa. Após este período, foi coletado sangue do plexo infraorbital e preparados esfregaços rapidamente corados com a coloração modificada de May-Grünwald-Giemsa para estudos hematológicos. Os valores de contagem de células sangüíneas vermelhas, hemoglobina, hematócrito, concentração de hemoglobina corpuscular média, hemoglobina corpuscular média, volume corpuscular médio e os valores de contagem total e diferencial de células sangüíneas brancas, obtidos antes e após tratamento, foram comparados.

\section{Toxicidade reprodutiva}

Camundongos albinos Swiss, pesando entre 20-30g, com idade em torno de 80-90 dias, foram distribuídos ao acaso em caixas de polipropileno de 30 x $40 \mathrm{~cm}$ (1 macho : 3 fêmeas) e observados toda manhã para detecção do plug vaginal, como diagnóstico do dia zero de gestação, sendo que este método de diagnóstico apresenta 91 a 93\% de estimativa de acerto (Szabo et al., 1969; Champlin, et al., 1973). À medida que era feita a comprovação de gestação, as fêmeas gestantes eram randomicamente separadas e os tratamentos com $147,3 \mathrm{mg} / \mathrm{kg}$ de EASa ou salina + tween $(0,1 \mathrm{~mL} / 10 \mathrm{~g})$ iniciados, por via oral através de gavagem. Em um dos experimentos, as fêmeas gestantes receberam EASa durante sete dias $(n=9)$, que corresponde ao período de implantação em ratas (Lemonica, 1996). Após três dias do término do tratamento, estas fêmeas foram sacrificadas, após anestesia com éter e por deslocamento cervical, e foi contado o número de locais de implantação, pontos de reabsorção e corpos lúteos, através de observação macroscópica com o auxílio de uma lupa. Em outro experimento, 147,3mg/kg/dia de EASa foi administrado do $1^{\circ}$ até o décimo quarto dia de gestação que corresponde ao período de implantação e organogênico em ratas (Lemonica, 1996), quando foi finalizado. As camundongas foram sacrificadas, conforme citado anteriormente, no vigésimo dia para a contagem de fetos vivos, pontos de reabsorção e corpos lúteos e observação de anomalias viscerais. Estes dados foram comparados para diferenças estatísticas entre os animais tratados com EASa e salina + tween (veículo). 


\section{Efeitos cardiovasculares}

Os efeitos de EASa no sistema cardiovascular foram avaliados na pressão sangüínea arterial média (PAM) e coração e átrio isolados de ratos. A PAM foi mensurada, em ratos wistar normotensos anestesiados com pentobarbital sódico (50mg/ kg; i.p), diretamente através de uma cânula implantada na artéria carótida e conectada a transdutores de pressão (P23 Statham, Gould, Oxnard, CA, USA) com registros em fisiógrafo. Os ratos foram impalados com eletrodos subcutâneos de platina e o eletrocardiograma (ECG) monitorado continuamente através de uma interface analógica digital acoplada a um instrumento computadorizado para aquisição de dados (Axon Instruments, Union City, CA, USA) e processados por Axo Scope 9.0. A seguir, as drogas teste foram injetadas com bólus na veia jugular através de um tubo de polietileno (PE20). Os efeitos de 0,$3 ; 1 ; 3$ e 10mg/kg de EASa foram avaliados e comparados com a administração isovolumétrica de salina + tween (controle negativo) e $40 \mathrm{mg} / \mathrm{kg}$ de acetilcolina (controle positivo). Em outra série de experimentos, os efeitos desta mesma variação de doses foram analisados em coração de rato perfundido. Os corações foram isolados de ratos Wistar e perfundidos via aorta a um fluxo constante $(10 \mathrm{~mL} / \mathrm{min})$ com uma solução modificada de Krebs-Henseleit (SKH) aerada com $95 \%$ de $\mathrm{O}_{2}$ em $5 \%$ de $\mathrm{CO}_{2}$. A SKH estava composta por (mM):166 de $\mathrm{NaCl} ; 4,75$ de $\mathrm{KCl} ; 1,2$ de $\mathrm{MgSO}_{4} ; 1,2$ de $\mathrm{NaH}_{2} \mathrm{PO}_{4}$; 25 de $\mathrm{NaHCO}_{3} ; 0,45$ de $\mathrm{CaCl}_{2}$ e 11 de glicose d glucose, modificada pela adição de $1 \mathrm{mg} / \mathrm{ml}$ de ácido ascórbico e dietilestilbestrol. Finalmente, os átrios foram isolados de ratos Wistar com o objetivo de estudar os efeitos de EASa na freqüência e força de contração separadamente. A atividade mecânica espontânea do átrio direito foi avaliada sob condições de controle interno (antes da administração de drogas) e depois com a adição de 1, 3, 10, 30 e $100 \mathrm{mg} / \mathrm{mL}$ de EASa ou veículo isovolumetricamente. Por outro lado, a atividade mecânica do átrio esquerdo estimulado eletricamente (pulsos de onda quadrada submaximais, $2 \mathrm{~Hz}$ e $5 \mathrm{~ms}$ ) foi estudada sob o mesmo protocolo. A freqüência dos batimentos espontâneos do átrio direito e a amplitude de contração do átrio esquerdo foram expressos como percentagem do controle interno (antes da administração de EASa) e comparados com os tecidos tratados com salina (controle negativo).

\section{Análise estatística}

Os dados foram reportados como média \pm erro-padrão da média (EP) de pelo menos cinco observações. A variação das observações e o intervalo de confiança de $95 \%$ foram apresentados para os dados bioquímicos e hematológicos. A comparação entre os grupos foi determinada pela análise de variança ANOVA seguida do teste de Tukey com o nível de significância estabelecido em 5\%. Quando apropriado o teste $t$ de Student foi aplicado para avaliar diferenças den- tro (pareado) e entre (não-pareado) os grupos. A CE ${ }_{50}$, definida aqui como a dose requerida para produzir metade do efeito máximo, foi calculada com os correspondentes $95 \%$ de intervalo de confiança pelo Graph Pad Prism Software. Os dados foram processados com inferência descritiva e estatística pelo Graph Pad Prism software versão 2.0 for Windows.

\section{Resultados}

A administração de EASa em doses correspondentes a $D_{1}$ ou $\mathrm{DL}_{10}$ não causou alterações significantes no comportamento padrão dos animais quando comparados com os animais tratados com salina. Os animais tratados com EASa, no experimento crônico, até tiveram um aumento líquido no ganho de peso corporal, que foi maior que o do grupo controle tratado com salina $(37,2 \pm 7,5 \%$ vs. $56,5 \pm 7,47 ; p<0,05)$. Os parâmetros bioquímicos analisados não foram notavelmente afetados pelos protocolos de tratamento usados (Tabelas 1 e 2). Os perfis séricos dos vários marcadores não foram alterados quando comparados com o controle interno, i.e., os valores obtidos antes dos tratamentos ou com os grupos tratados com salina. A análise histopatológica não revelou alterações na estrutura padrão dos tecidos estudados. Por isso, a administração da $\mathrm{DL}_{1}$ e $\mathrm{DL}_{10}$ de EASa a ratos durante 30 ou 60 dias não induziu manifestações significantes sistêmicas de toxicidade.

Similarmente, os perfis hematológicos de seis ratos não foram afetados, exceto pelo valor de VCM, que foi significante maior no grupo tratado $(66,5 \pm 1,6$ fl. vs. $89,8 \pm 1,2, p<0,001)$ (Tabela 3).

Após sete dias recebendo oralmente $a \mathrm{DL}_{10}$ de $\mathrm{EASa}$, o número de locais de implantação no décimo dia de gestação não foi significantemente diferente $(7,7 \pm 1$ vs. $8,6 \pm 1,5)$ quando comparado com os animais tratados com salina. $O$ número de corpos lúteos permaneceu inalterado, sendo 8,6 $\pm 0,6$ para o grupo tratado com EASa e $10,3 \pm 0,6$ para o grupo

Tabela 1 - Parâmetros bioquímicos de ratos Wistar antes e depois do tratamento por 30 dias com 73,3mg/kg/dia (DL $)$ de extrato acetato de etila de Spigelia anthelmia (EASa) ou $150 \mathrm{mg} / \mathrm{kg} / \mathrm{dia}\left(\mathrm{DL}_{10}\right)$ de EASA ou veículo

\begin{tabular}{lcccccccc}
\hline & \multicolumn{7}{c}{ Parâmetros Bioquímicos $/$ Toxicidade Subcrônica } \\
\cline { 2 - 9 } Grupos & Albumina & Uréia & Creatinina & TGO & TGP & Bilirrubina & Bilirrubina & Bilirub. \\
& & & & & & Total & Direta & Indireta \\
\hline Controle & $3.03 \pm 0.62$ & $44 \pm 3.1$ & $0.45 \pm 0.03$ & $50.5 \pm 1.7$ & $15.1 \pm 1.4$ & $0.18 \pm 0.03$ & $0.04 \pm 0.004$ & $0.11 \pm 0.03$ \\
& $(n=10)$ & $(n=10)$ & $(n=10)$ & $(n=8)$ & $(n=7)$ & $(n=10)$ & $(n=7)$ & $(n=7)$ \\
Veículo & $3.8 \pm 0.18$ & $40.3 \pm 3.0$ & $0.41 \pm 0.011$ & $46.9 \pm 2.05$ & $17.0 \pm 1.0$ & $0.17 \pm 0.019$ & $0.03 \pm 0.003$ & $0.14 \pm 0.06$ \\
& $(n=9)$ & $(n=9)$ & $(n=9)$ & $(n=9)$ & $(n=9)$ & $(n=9)$ & $(n=9)$ & $(n=9)$ \\
Controle & $3.15 \pm 0.12$ & $43.9 \pm 2.3$ & $0.42 \pm 0.015$ & $42.8 \pm 2.4$ & $15.0 \pm 1.7$ & $0.18 \pm 0.017$ & $0.05 \pm 0.017$ & $0.13 \pm 0.02$ \\
& $(n=10)$ & $(n=9)$ & $(n=9)$ & $(n=8)$ & $(n=8)$ & $(n=9)$ & $(n=8)$ & $(n=8)$ \\
EASa & $4 \pm 0.17$ & $41.0 \pm 3.4$ & $0.44 \pm 0.016$ & $43.5 \pm 2.8$ & $16.4 \pm 1.5$ & $0.18 \pm 0.017$ & $0.04 \pm 0.007$ & $0.13 \pm 0.015$ \\
DL 1 & $(n=10)$ & $(n=10)$ & $(n=10)$ & $(n=10)$ & $(n=10)$ & $(n=9)$ & $(n=9)$ & $(n=10)$ \\
Controle & $3.44 \pm 0.11$ & $48.1 \pm 1.8$ & $0.4 \pm 0.023$ & $40.5 \pm 1.2$ & $16.1 \pm 1.7$ & $0.17 \pm 0.021$ & $0.05 \pm 0.006$ & $0.15 \pm 0.02$ \\
& $(n=10)$ & $(n=10)$ & $(n=9)$ & $(n=10)$ & $(n=10)$ & $(n=10)$ & $(n=7)$ & $(n=6)$ \\
EASa & $3.9 \pm 0.13$ & $45.7 \pm 2.5$ & $0.44 \pm 0.026$ & $43.4 \pm 1.5$ & $14.4 \pm 0.9$ & $0.16 \pm 0.013$ & $0.05 \pm 0.010$ & $0.10 \pm 0.019$ \\
DL ${ }_{10}$ & $(n=10)$ & $(n=10)$ & $(n=10)$ & $(n=10)$ & $(n=10)$ & $(n=9)$ & $(n=10)$ & $(n=10)$ \\
\hline
\end{tabular}


Tabela 2 - Parâmetros bioquímicos de ratos Wistar antes e depois de tratamento oral durante 60 dias com 147,3mg/ $\mathrm{kg} /$ dia $\left(\mathrm{DL}_{10}\right)$ com extrato acetato de etila de Spigelia anthelmia (EASA) ou veículo

\begin{tabular}{lcccc}
\multirow{2}{*}{ PARÂMETROS } & \multicolumn{2}{c}{ Dia Zero } & \multicolumn{2}{c}{30 dias após tratamento com EASA } \\
\cline { 2 - 5 } & Média \pm EP & IC $(95 \%)$ & Média \pm EP & IC $(95 \%)$ \\
\hline Hemácias $\left(\mathrm{mm}^{3}\right)$ & $6875000 \pm 188900$ & $6389000-7361000$ & $6250000-176500$ & $5796000-6704000$ \\
Hemoglobina: $\mathrm{g} / \mathrm{dL}$ & $14.63 \pm 0.61$ & $13.06-16.21$ & $14.97 \pm 0.30$ & $14.20-15.74$ \\
Hematócrito: $\%$ & $45.33 \pm 0.56$ & $43.90-46.77$ & $48.17 \pm 0.54$ & $46.77-49.56$ \\
VCM (fl) & $66.50 \pm 1.65$ & $62.26-70.74$ & $89.83 \pm 1.17$ & $86.83-92.83$ \\
HCM (pg) & $21.17 \pm 0.75$ & $19.24-23.09$ & $24 \pm 0.82$ & $21.90-26.10$ \\
CHCM (\%) & $32.17 \pm 1.11$ & $29.32-35.62$ & $31.17 \pm 0.48$ & $29.94-32.39$ \\
Leucócitos & $18950 \pm 2032$ & $13730-24170$ & $10880 \pm 1271$ & $7616-14150$ \\
Neutrófilos & $4901 \pm 590$ & $3383-6416$ & $2183 \pm 321$ & $1757-3008$ \\
Bastonetes & $23.30 \pm 15.68$ & $-12.18 \pm 58.78$ & 0 & 0 \\
Segmentados & $4881 \pm 588$ & $3370-6392$ & $2183 \pm 321$ & $1757-3008$ \\
Eosinófilos & $522 \pm 84.82$ & $304-740$ & $253 \pm 84.5$ & $36.05-470.3$ \\
Basófilos & 0 & 0 & 0 & 0 \\
Linfócitos & $13280 \pm 2040$ & $8034-18520$ & $8307 \pm 988$ & $5766-10850$ \\
Monócitos & $250 \pm 41.4$ & $143-356$ & $109 \pm 12.7$ & $76.2-141$ \\
\hline
\end{tabular}

\begin{tabular}{|c|c|c|c|c|c|c|c|c|}
\hline \multirow[b]{2}{*}{ Grupos } & \multicolumn{8}{|c|}{ Parâmetros Bioquímicos / Toxicidade Crônica } \\
\hline & Albumina & Uréia & Creatinina & TGO & TGP & $\begin{array}{l}\text { Bilirrubina } \\
\text { Total }\end{array}$ & $\begin{array}{l}\text { Bilirrubina } \\
\text { Direta }\end{array}$ & $\begin{array}{l}\text { Bilirrubina } \\
\text { Indireta }\end{array}$ \\
\hline Controle & $\begin{array}{c}2.98 \pm 0.24 \\
(n=5)\end{array}$ & $\begin{array}{c}37.5 \pm 2.19 \\
(n=5)\end{array}$ & $\begin{array}{c}0.38 \pm 0.02 \\
(n=5)\end{array}$ & $\begin{array}{c}42.9 \pm 3.9 \\
(n=5)\end{array}$ & $\begin{array}{c}15.5 \pm 1.4 \\
(n=5)\end{array}$ & $\begin{array}{c}0.16 \pm 0.03 \\
(n=5)\end{array}$ & $\begin{array}{c}0.03 \pm 0.007 \\
(n=3)\end{array}$ & $\begin{array}{c}0.10 \pm 0.014 \\
(n=3)\end{array}$ \\
\hline Veículo & $\begin{array}{c}3.3 \pm 0.14 \\
(n=6)\end{array}$ & $\begin{array}{c}57.7 \pm 2.9 \\
(n=5)\end{array}$ & $\begin{array}{c}0.5 \pm 0.077 \\
(n=5)\end{array}$ & $\begin{array}{c}46.6 \pm 1.1 \\
(n=5)\end{array}$ & $\begin{array}{c}17.3 \pm 2.9 \\
(n=5)\end{array}$ & $\begin{array}{c}0.17 \pm 0.012 \\
(n=5)\end{array}$ & $\begin{array}{c}0.05 \pm 0.014 \\
(n=5)\end{array}$ & $\begin{array}{c}0.12 \pm 0.027 \\
(n=5)\end{array}$ \\
\hline Controle & $\begin{array}{c}3.35 \pm 0.13 \\
\quad(n=8)\end{array}$ & $\begin{array}{c}47.7 \pm 3.5 \\
(n=8)\end{array}$ & $\begin{array}{c}0.4 \pm 0.012 \\
\quad(n=8)\end{array}$ & $\begin{array}{c}43.3 \pm 2.2 \\
(n=8)\end{array}$ & $\begin{array}{c}17.3 \pm 2.0 \\
(n=8)\end{array}$ & $\begin{array}{c}0.17 \pm 0.017 \\
(n=8)\end{array}$ & $\begin{array}{c}0.04 \pm 0.003 \\
(n=6)\end{array}$ & $\begin{array}{r}0.12 \pm 0.02 \\
(n=6)\end{array}$ \\
\hline EASA & $\begin{array}{c}3.2 \pm 0.16 \\
(n=8)\end{array}$ & $\begin{array}{c}56.1 \pm 1.9 \\
(n=8)\end{array}$ & $\begin{array}{c}0.46 \pm 0.026 \\
(n=8)\end{array}$ & $\begin{array}{c}51.3 \pm 1.5 \\
(n=8)\end{array}$ & $\begin{array}{c}20.6 \pm 2.2 \\
(n=8)\end{array}$ & $\begin{array}{c}0.2 \pm 0.022 \\
(n=8)\end{array}$ & $\begin{array}{c}0.04 \pm 0.004 \\
(n=8)\end{array}$ & $\begin{array}{c}0.16 \pm 0.020 \\
(n=8)\end{array}$ \\
\hline
\end{tabular}

Tabela 3 - Parâmetros hematológicos de ratos Wistar antes e depois de tratamento oral com $147,3 \mathrm{mg} / \mathrm{kg} / \mathrm{dia}$ $\left(\mathrm{DL}_{10}\right)$ de extrato acetato de etila de Spigelia anthelmia (EASA) ou veículo tratado com salina. Similarmente, o grupo tratado com EASa do 1 ao 14 dia de gestação não mostrou diferenças quando comparado ao grupo tratado com salina para fetos vivos. O número de fetos vivos foi de $8,2 \pm 0,6$ no grupo tratado com EASa e 7,2 $\pm 0,5$ no grupo tratado com veículo (Figura 1). A avaliação macroscópica dos fetos não mostrou qualquer alteração externa ou visceral.

A administração intravenosa de baixas doses de EASa induziu um pequeno aumento na PAM equivalente àquela obtida após injeção isovolumétrica de veículo. A maior dose usada $(10 \mathrm{mg} / \mathrm{kg})$ diminuiu a PAM com início rápido e de curta duração ( $<1 \mathrm{~min})$. Este efeito não foi equivalente à diminuição induzida por $1 \mathrm{mg} / \mathrm{kg}$ de acetilcolina, usada como controle positivo $(20,4 \pm 10,5 \mathrm{mmHg}$ vs. $56,6 \pm 9,7 \mathrm{mmHg}$, respectivamente) (Figura 2). Além disso, este efeito da EASa na PAM não foi acompanhado por uma alteração significante na freqüência cardíaca ou nos parâmetros eletrocardiográficos estudados (Figura 3 e Tabela 4). A freqüência cardíaca antes da administração de EASa foi de $333,8 \pm 28,9$ e, após a maior dose usada (10mg/kg), a freqüência variou para $322,3 \pm 28,1$ batimentos por minuto $(p>0,05)$.
A administração de EASa como bólus em injeção até 10 mgnão foi capaz de induzir alguma alteração na freqüência dos batimentos espontâneos do coração isolado (Figura 4). A freqüência variou de valores do controle de 162,6 \pm 18,1 para 176,2 ( $6 \pm 0,7 \%$ de variação). Similarmente, a freqüência da atividade espontânea mecânica do átrio direito (Figura 5) não foi alterada após adição cumulativa de EASa ao meio do banho até $100 \mathrm{mg} / \mathrm{mL}(452,5 \pm 54,9$ para $407,5 \pm 45,7-9,9 \pm 2,5$ $\%$ de variação).

O EASa induziu um decréscimo significante na amplitude de contração do coração perfundido isolado (Figura 6) e na amplitude da atividade mecânica de átrio esquerdo eletricamente estimulado (Figura 7). As injeções de EASa em bólus nas doses 0,$3 ; 1 ; 3$ e 10mg reduziram a amplitude de contração do coração para $11 \pm 2,3 \%, 23 \pm 6 \%, 33 \pm 7 \%$ e $64 \pm 11 \%$ ( $p<0,05$ vs. veículo), respectivamente (Figura 6). A $\mathrm{CE}_{50}$ para este efeito foi de 7,5mg [5,5-9,5]. Similarmente, a incubação do átrio esquerdo estimulado eletricamente com 30 e $100 \mathrm{mg} / \mathrm{mL}$ reduziu a amplitude de contração em $30,6 \pm 11,9 \%$ e $55,4 \pm 12,7 \%$, respectivamente (Figura 7). A CE $\mathrm{E}_{50}$ para esta redução da amplitude no átrio esquerdo foi de $48,3 \mathrm{mg} / \mathrm{mL}[12,1-194,2]$. 

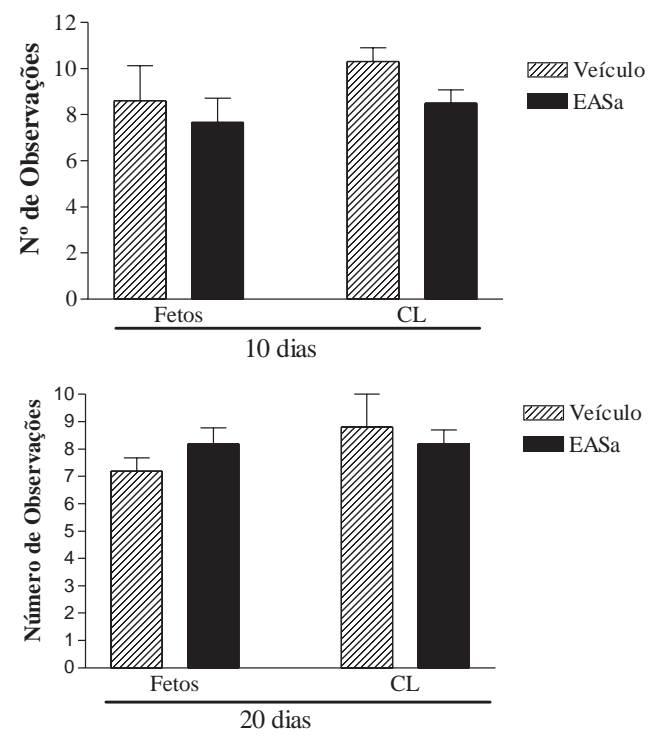

Figura 1 - Número de fetos e corpos lúteos em animais tratados com extrato acetato se etila de Spigelia anthelmia (EASa) e salina (controle) durante os sete (1a) e os 14 (1b) dias iniciais de gestação em camundongas

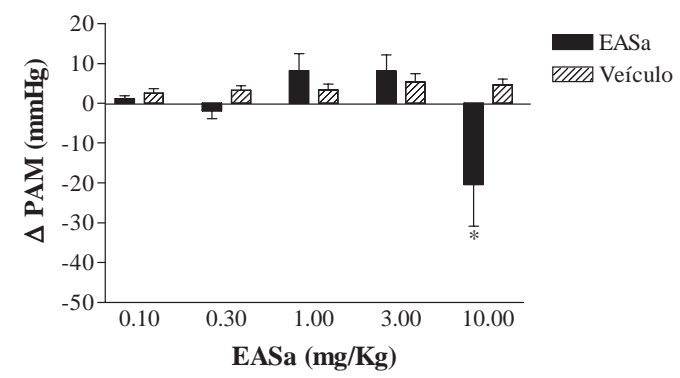

Figura 2 - Efeito do extrato acetao de etila (EASa) de Spigelia anthelmia sobre a média da pressão arterial de ratos normnotensos.

Os dados são apresentados como média \pm erro-padrão da média. ${ }^{*} p<0,05$.

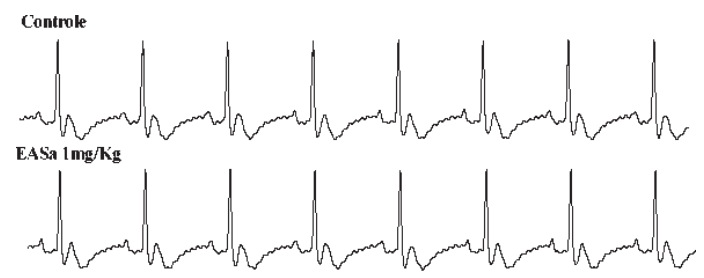

EASA 3mg/Kg

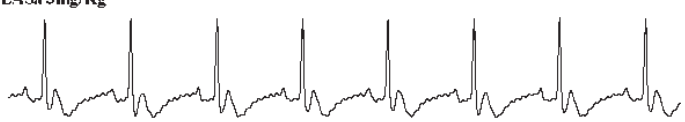
EASa $10 \mathrm{mg} / \mathrm{kg}$

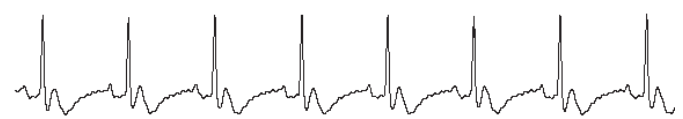<smiles></smiles>

Figura 3 - Traçado original representativo do efeito do extrato acetato de etila $(1-10 \mathrm{mg} / \mathrm{kg})$ de Spigelia anthelmia sobre parâmetros eletrocardiográficos de ratos anestesiados
Tabela 4 - Efeitos do extrato acetato de etila de Spigelia anthelmia (EASa) nos parâmetros eletrocardiográficos em ratos anestesiados

\begin{tabular}{lccc}
\hline \multicolumn{1}{c}{ DOSE } & P $(\mathrm{A}-\mathrm{D})$ & QRS $(\mathrm{A}-\mathrm{D})$ & $\mathrm{T}(\mathrm{A}-\mathrm{D})$ \\
\hline Veículo & $0.14 \pm 0.03-16.1 \pm 1.3$ & $2.21 \pm 0.6-28.2 \pm 2.8$ & $0.47 \pm 0.036-33 \pm 2.8$ \\
EASa $1 \mathrm{mg} / \mathrm{kg}$ & $0.138 \pm 0.05-16.0 \pm 1.3$ & $2.12 \pm 0.43-24.6 \pm 2.3$ & $0.51 \pm 0.06-34 \pm 3.1$ \\
EASa $3 \mathrm{mg} / \mathrm{kg}$ & $0.143 \pm 0.04-23.4 \pm 2.7$ & $2.1 \pm 0.36-30.6 \pm 3.1$ & $0.47 \pm 0.036-35 \pm 2.1$ \\
EASa $10 \mathrm{mg} / \mathrm{gk}$ & $0.151 \pm 0.06-22.5 \pm 1.8$ & $1.79 \pm 0.26-39.5 \pm 3.6$ & $0.47 \pm 0.036-35 \pm 2.1$ \\
\hline${ }^{*}$ INTERVALOS $(\mathrm{ms})-{ }^{*}$ *SEGMENTOS (ms) & &
\end{tabular}

\begin{tabular}{ccccc}
\hline $\mathrm{PR}$ & $\mathrm{QT}(\mathrm{ms})$ & $\mathrm{Q} \mathrm{T}_{\mathrm{C}}$ & $\mathrm{RR}(\mathrm{ms})$ & $\mathrm{ST}(\mathrm{ms})$ \\
\hline${ }^{*} 52.3 \pm 4.7-^{* *} 31.4 \pm 2.4$ & $79.7 \pm 5.9$ & $5.3 \pm 0.62$ & $235.1 \pm 21.5$ & $43.6 \pm 3.7$ \\
${ }^{*} 51.5 \pm 3.8-^{* *} 26.6 \pm 1.9$ & $77.3 \pm 4.7$ & $5.02 \pm 0.63$ & $236.7 \pm 22.4$ & $45.1 \pm 3.8$ \\
${ }^{*} 51.5 \pm 3.8-{ }^{* *} 32.2 \pm 2.3$ & $73.3 \pm 4.7$ & $5.33 \pm 0.63$ & $235.1 \pm 20.4$ & $42.7 \pm 2.8$ \\
${ }^{*} 52.3 \pm 3.6-{ }^{* *} 30.6 \pm 2.1$ & $73.3 \pm 4.7$ & $4.71 \pm 0.53$ & $242.4 \pm 23.7$ & $43.5 \pm 3.4$ \\
\hline
\end{tabular}

$\mathrm{A}=$ amplitude em milivolts (mv), D = duração em milissegundos (ms)

QTC = intervalo QT corrigido

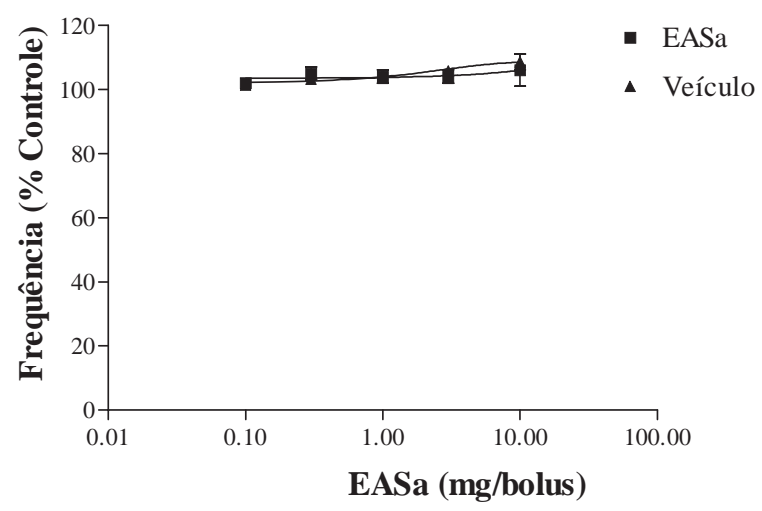

Figura 4 - Efeito de $0.1,0.3,1,3$ e $10 \mathrm{mg} / \mathrm{kg}$ de extrato acetato de etila (EASa) injetado em bolus via aorta na freqüência de contrações do coração isolado.

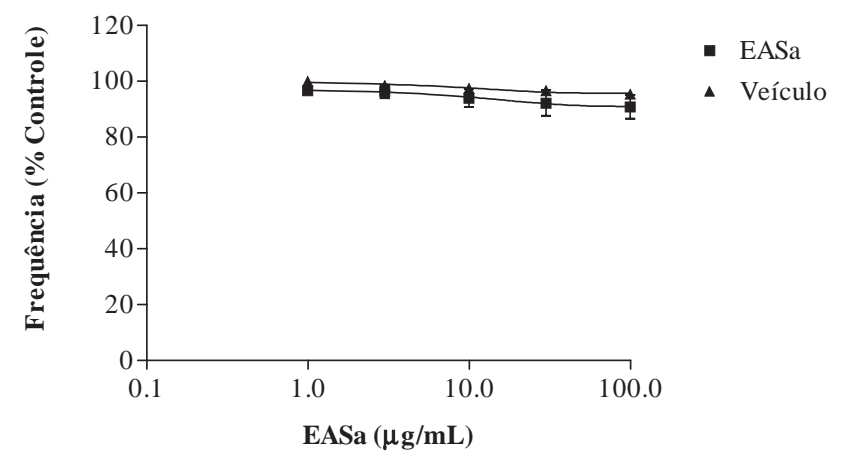

Figura 5 - Efeito de $0.1,0.3,1,3$ e $10 \mathrm{mg} / \mathrm{kg}$ do extrato acetato de etila (EASa)de Spigelia anthelmia sobre a freqüência de contrações do átrio direito. Os dados são apresentados como média \pm erro-padrão da média. 


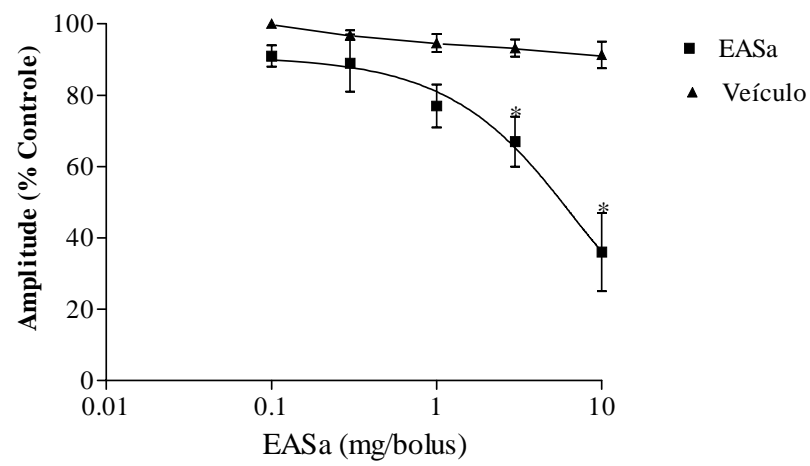

Figura 6 - Efeito da adição de $0.1,0.3,1,3$ e $10 \mathrm{mg} / \mathrm{kg}$ de extrato acetato de etila de Spigelia anthelmia (EASa) em bólus na amplitude de contração do coração isolado de rato comparado com tecidos tratados com veículo, isovolumetricamente. Os dados são apresentados como média \pm erro-padrão da média. ${ }^{*} p<0,05$.

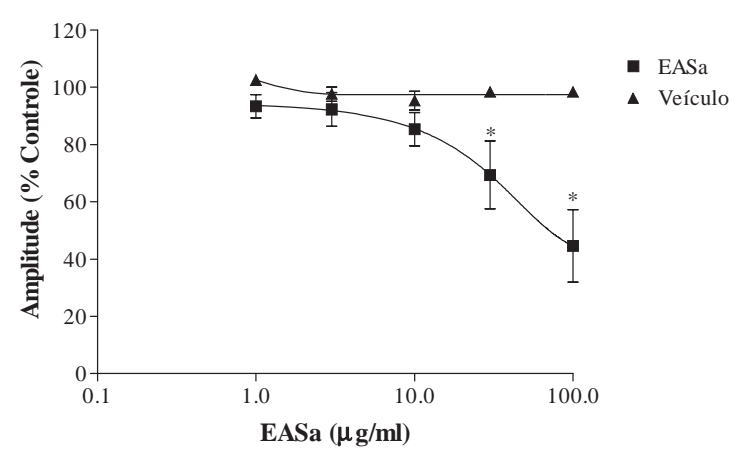

Figura 7 - Efeito do extrato acetato de etila de Spigelia anthelmia (EASa) $(1$ a $10 \mathrm{mg} / \mathrm{ml}$ ) sobre a amplitude de contrações causadas por estímulo elétrico no átrio esquerdo.

Os dados são apresentados como média \pm erro-padrão da média. ${ }^{*} p<0,05$.

\section{Discussão}

As partes aéreas de $S$. anthelmia são amplamente usadas na medicina popular do Brasil como anti-helmíntico. A eficácia de alguns extratos orgânicos foi validada, in vitro, por Batista et al. (1999) e Assis (2000). Porém, não existem relatos científicos sobre a segurança após administração aguda ou prolongada. Recentemente, Camurça-Vasconcelos (2002) relatou seus efeitos agudos em camundongos e pintos e sua atividade bloqueadora neuromuscular levando à paralisia tônica.

O presente estudo revelou que a administração até 60 dias de uma dose correspondente a $\mathrm{DL}_{10}$ não afetou qualquer parâmetro bioquímico, hematológico ou reprodutivo estudado. A exceção a esta declaração é uma leve alteração nos níveis de TGO observada nos grupos tratados com 147,3mg/ $\mathrm{kg}$ de EASa. Contudo, o aumento nos níveis séricos de TGO (de $43,3 \pm 2,2 \mathrm{mg} / \mathrm{dL}$ para $51,3 \pm 1,5 \mathrm{mg} / \mathrm{dL} ; \mathrm{n}=8 ; \mathrm{p}<0.05$ ), apesar da diferença estatisticamente significante, é de pequena significância clínica. Realmente, o nível obtido após o tratamento estava dentro da variação de valores de referência para esta espécie (Mitruka e Ramsley, 1977; Shanker et al., 2002) e dentro da variação dos valores controle obtidos em animais normais antes do tratamento $(28,5-58,2 \mathrm{mg} / \mathrm{dL})$ (Tabela 3$)$. $\mathrm{O}$ aumento de TGO não foi acompanhado por nenhuma alteração em TGP, bilirrubina ou albumina e pode refletir uma variação fisiológica antes do que uma manifestação toxicológica. Mesmo assim, longos períodos de administração necessitam ser realizados para esclarecer se esta alteração é uma manifestação inicial tóxica ou somente uma flutuação normal sob a variação fisiológica. Além disso, uma vez que EASa está sendo testado para sua eficácia anti-helmíntica para nematódeos gastrintestinais e para sua segurança com relação ao hospedeiro, o período de administração é suficiente para atestar que este extrato é imparcialmente seguro para administração oral em protocolos com dosagens simples ou repetidas como proposta terapêutica até o limite da $\mathrm{DL}_{10}$.

A contagem de células vermelhas do sangue também foi normal após tratamento durante 30 dias com EASa e nenhuma alteração foi observada no hematócrito ou valores de hemoglobina. As plaquetas também permaneceram inalteradas em número e forma. Por isso, a administração por longo prazo de EASa é improvável causa de danos diretos nas células sangüíneas, na medula óssea ou de anormalidades na absorção ou incorporação de nutrientes necessários para a eritropoiese, pelo menos num grau suficiente para causar anemia. Similarmente, a administração durante 30 dias de EASa não causou efeitos significantes na contagem total ou diferencial das células sangüíneas da linhagem branca. Assim, estes efeitos dão suporte à falta de efeitos tóxicos induzidos por EASa diretamente nas células sangüíneas e nenhum dano direto à medula óssea. Além do mais, uma atividade imunodepressora deste extrato é também improvável.

Em outros aspectos, a falência na implantação embrionária pode ser relacionada com a exposição maternal a agentes químicos que podem interferir com este evento por diferentes mecanismos. Isto inclui alterações morfológicas no embrião que interferem com a implantação ou promovem embrioletalidade; modificação dos níveis hormonais, assim interferindo com a implantação embrionária; alteração das condições uterinas necessárias para nidação, ou distúrbios no transporte tubáreo, e conseqüente interferência com o tempo correto de chegada do blastocisto no útero (Cummings, 1990).

A administração de EASa no período de pré-implantação não induziu diminuição estatisticamente significante no número de locais de implantação. Isto pode insinuar que o extrato não afeta qualquer dos passos necessários para nidação e implantação dos embriões. Similarmente, a administração de $147,3 \mathrm{mg} / \mathrm{kg}$ de EASa durante o período organogênico a camundongas prenhes não afetou a taxa de concepção (embrioletalidade) e não causou malformações externas ou viscerais (teratogenia).

A administração de EASa (i.v) em bólus não teve efeitos significantes na pressão arterial média de ratos normotensos anestesiados. A maior dose usada $(10 \mathrm{mg} / \mathrm{kg}$ ) induziu um leve efeito hipotensivo de início rápido e de curta duração com pouco impacto hemodinâmico. Além do mais, o extrato não induziu um decréscimo concomitante na taxa cardíaca ou alteração no perfil do ECG. Este último efeito mostra que este extrato não tem potencial arritmogênico.

Achenbach et al., (1995) relatam que um extrato de $S$. anthelmia e a espigantina e outros compostos tipo rianodina isolados desta espécie aumentam a latência da contração de músculo papilar de porquinhos-da-índia (atividade 
cardiodepressora). Entretanto, o extrato acetato de etila de $S$. anthelmia é desprovido de qualquer efeito na freqüência espontânea dos batimentos em ratos e somente na mais alta dose foi capaz de diminuir a amplitude de contração do coração inteiro isolado perfundido e a amplitude de contração do átrio esquerdo estimulado eletricamente. Isto pode sugerir que o efeito cardiodepressor encontrado no músculo papilar de porquinhos-da-índia (Hübner et al,. 2001) é irrelevante para o coração inteiro e para a função isolada do átrio. Isto é mais fortemente suportado pela falta de efeito significativo do EASa na PAM ou nos parâmetros de ECG estudados.
A administração por longo prazo da $\mathrm{DL}_{1}$ ou $\mathrm{DL}_{10}$ de EASa é rigorosamente segura e é provavelmente desprovida de toxicidade significativa. Além de tudo, os alcalóides tipo rianodina que foram isolados desta espécie (Morais et al, 2002) podem ser responsáveis por sua reputada atividade bloqueadora neuromuscular (Camurça-Vasconcelos, 2002) e o uso desta planta em triagens clínicas de caprinos ou outras espécies domésticas necessita ser precedida de determinação rigorosa de sua segurança específica e de uma janela terapêutica.

\section{Agradecimentos}

Gostaríamos de agradecer ao LabTeste pela generosa doação de reagentes bioquímicos, ao CNPq (protocolo 46390/01), FUNCAP (protocolo 147/00) e CAPES pelo suporte financeiro, ao laboratório de Histologia da Universidade Estadual do Ceará e Maria do Carmo de Oliveira, pela valiosa assistência no estudo histológico, e ao IBIMED (Instituto de Biomedicina - UFC) pela especial recepção e colaboração.

\section{Referências}

ACHENBACH, H.; HÜBNER, H.; VIERLING, W.;BRANDT, W.; REITER, M. Spiganthine, the cardioctive principle of Spigelia anthelmia. J. Nat. Prod., v. 58, p. 1092-1096, 1995.

ASSIS, L. M. Atividade anti-helmíntica in vitro de extratos de Spigelia anthelmia sobre Haemonchus contortus. 2000. 44 f. Dissertação (Mestrado)—Faculdade de Medicina Veterinária - Universidade Estadual do Ceará, 2000.

BARROS, S. B. M.; DAVINO, S. C. Avaliação de toxicidade. In: OGA, S. Fundamentos de toxicologia. São Paulo: Atheneu, 1996. p.87-94.

BASÍLIO, I. J. L. D.; SILVA, K. N.; AGRA, M. F. Etnomedicina e farmacobotânica das Loganiáceas da Mata Atlântica Paraibana, Brasil. Anais do IX Encontro de Iniciação Científica da Universidade Federal da Paraíba, v. 01.10.07., 2001.

BATISTA, L.M.; BEVILAQUA, C. M. L.; VIEIRA, L. S.; MORAIS, S. M. Atividade ovicida e larvicida in vitro das plantas Spigelia anthelmia e Momordica charantia sobre o nematódeo de ovinos Haemonchus contortus. Ciência Animal, v. 9, p. 67-73, 1999.

BRAGA, R. Plantas do nordeste, especialmente do Ceará. 3. ed. Coleção Mossoroense XLII, p. 322-323, 1976.

CAMURÇA-VASCONCELOS, A. L. F. Estudo farmacológico e toxicológico do extrato acetato de etlia de Spigelia anthelmia Linn em animais de laboratório. 2002. 93 f. Dissertação (Mestrado)—Faculdade de Medicina Veterinária - Universidade Estadual do Ceará, 2002.

CHAMPLIN, A. K.; DORR, D. L.; GATES, A. H. Determining the stage of the estrous cycle in the mouse by the appearance of the vagina. Biology of Reproduction, v. 8, p. 491-494, 1973.
CUMMINGS, A.M. Toxicological mechanisms of implantation failure. Fundam Appl Toxicol, v. 15, n. 3, p. 571-579, 1990.

HÜBNER, H.; VIERLING, W.;BRANDT, W.; REITER, M.; ACHENBACH, H. Minor constituents of Spigelia anthelmia and their cardiac activities. Phytochemistry, v. 57, p. 285-296, 2001.

LEMONICA, I. P. Embriofetotoxicidade. In: OGA, S. Fundamentos de toxicologia. São Paulo: Atheneu, 1996. p. 87-94.

MITRUKA B. M.; RAMSLEY, H. M. Clinical biochemical and hematological reference values in normal experimental animals. New York: Masson Publishing, 1977.

MORAIS, S. L.; BEVILAQUA, C. M. L.; SOUZA, J. A.; ASSIS, L. M. Chemical investigation of Spigelia anthelmia Linn. used in Brazilian folk medicine as an anthelmintic. Revista Brasileira de Farmacognosia, v. 12, suplemento, p. 81-82, 2002.

SHANKER, K.; PATHAK, N. K. R.; TRIVEDI, V. P.; CHANSURIA, J. P. N.; PANDEY, V. B. An evaluation of toxicity of Taxus baccata Linn. (Talispatra) in experimental animals. J. of etnopharmacology, v. 79, n. 1, p. 69-73, 2002.

SZABO, K. T.; FREE, S. M.; BIRKHEAD, H. A.; GAY, P. E. Predictability of pregnancy from various signs of maitting in mice and rats. Laboratory Animal Care, v. 19, p. 822-825, 1969.

WAGNER, H.; SEEGERT, K.; ODENTHAL, K. P.; ESPOSITO. M.; VILARREAL, E.; SOLIS, G.P.; GUPTA, M. P. Preliminary pharmacologic evaluation of Spigelia anthelmia aerial parts. Int. J. Pharmacog. v. 31, p. 7-14, 1993. 
